\title{
Trombositten Zengin Materyaller ve Periodontolojideki Kullanımı
}

\author{
Platelet-Rich Materials and Use in Periodontology
}

\section{H. Ebru Olgun ERDEMİR ${ }^{1}$, Serdar Yücel ÖZKAN ${ }^{1}$}

${ }^{1}$ Kırıkkale Üniversitesi, Diş Hekimliği Fakültesi, Periodontoloji A.D., KIRIKKALE

\begin{abstract}
ÖZET
Periodontal tedavinin amacı bireyin doğal dişlerini tüm yaşamı boyunca optimal fonksiyon, estetik ve rahatllk sağlayacak biçimde korumak ve sürdürmektir. Optimal periodontal tedavi, kaybolan periodonsiyumun rejenerasyonunu içermektedir. Geleneksel tedaviler sonucunda, ideal koşullar altında bile çoğu zaman uzun epiteliyal ataşman, sınırlı miktarda kemik, sement ve bağ dokusu oluşumu gerçekleşmektedir. Ancak son 20 y1ldır, periodontal cerrahiyi takiben periodontal rejenerasyonu oluşturmaya yönelik çalışmalar yoğunlaşmıştır. Periodontal dokuların gelişimi ve rejenerasyonu için kritik olan faktör, uygun hücrelerin yara alanına çekilmesidir. Son zamanlarda periodontal rejenerasyonu sağlamak üzere taşıyıcı olarak da işlev gören biyolojik veya sentetik yapılar, otojen hücreler, aracı moleküller ve büyüme faktörleriyle birlikte kullanılmaya başlanmıştır. Doğal yara iyileşmesinde temel rol oynayan büyüme faktörü kompleksinin ana kaynağı trombositlerdir. Trombositler sadece pıhtı şekillendirerek lokal kan ve lenf kaybını önlemekle kalmaz aynı zamanda yara iyileşmesini başlatan büyüme faktörlerini ve sitokinleri içerir.

Son yıllarda geliştirilen trombositten zengin plazma (TZP) ve trombositten zengin fibrin (TZF) uygulamaları, doğal pıhtıdaki eritrosit/trombosit oranını tersine çevirerek, büyüme faktörlerinin konsantre halde cerrahi bölgesine uygulanmasını sağlamakta, yara iyileşmesini ve rejenerasyonu hızlandırmaktadır.

$\mathrm{Bu}$ derlemenin amac1; periodontal rejeneratif tedavide yeni bir yaklaşım olan trombosit kaynaklı ürünlerin etkinlik mekanizması, hazırlanışı ve periodontolojideki klinik kullanım alanları ile ilgili bilgi vermektir.
\end{abstract}

Anahtar Kelimeler: Trombosit, fibrin, rejenerasyon

\begin{abstract}
The aim of the periodontal treatment during the whole life of the individual is to protect and maintain the optimal function, aesthetic and comfort of natural teeth. Optimal periodontal therapy include the periodontal regeneration of the lost periodontium. Even under ideal conditions, most of the time a long epithelial attachment, a limited amount of bone, cementum, and connective tissue formation take place as a result of traditional treatments. But in the last 20 years, it has been studied for creating periodontal regeneration after the periodontal surgery. The critical factor for the development and regeneration of periodontal tissues, orientation of the appropriate cells to the wound area. Recently, biological or synthetic structures also function as a carrier to provide the periodontal regeneration have been used together with autologous cells, the mediator molecules and growth factors. Platelets are the main source of the growth factor complex that play an important role in the wound healing. Platelets not only shaping the clot for preventing the loss of blood and lymph but also contain growth factors and cytokines that start wound healing.

In recent years, developed platelet-rich plasma (PRP) and platelet-rich fibrin (PRF) applications, reversed erythrocyte/ platelet ratio in the natural clot, thus provide the application of growth factors to the surgical site as concentrate form and accelerate wound healing and regeneration.

The purpose of this review, is to give information about the clinical indications, mechanism and preparation of the plateletderived products as a new approach to the periodontal regenerative treatment.
\end{abstract}

Keywords: Platelet, fibrin, regeneration
KÜ Tıp Fak Derg 2014; 16(1): 18-22

Geliş Tarihi / Received: 23.12.2013

Kabul Tarihi / Accepted: 06.02.2014
Yazışma Adresi / Correspondence: Serdar Yücel ÖZKAN KÜ Diş Hekimliği Fakültesi, Periodontoloji A.D., KIRIKKALE

E-posta: srdrozkan@gmail.com Tel: 3182244927 


\section{GÍRIŞ}

Optimal periodontal tedavi, kaybolan periodonsiyumun rejenerasyonunu içermektedir (1). Dişin apikalinden koronaline doğru uzanan yeni sement oluşumu, yeni sement ve yeni kemik arasında uzanan fonksiyonel olarak düzenlenmiş periodontal ligament fibrilleri ile rezidüel alveoler interdental septumdan koronale doğru uzanan yeni supra krestal kemik oluşumunun sağlanması ile rejenerasyon başarılmış olur (2). Geleneksel tedaviler sonucunda, ideal koşullar altında bile çoğu zaman uzun epiteliyal ataşman, sınırlı miktarda kemik, sement ve bağ dokusu oluşumu gerçekleşmektedir. Ancak son 20 yıldır, periodontal cerrahiyi takiben periodontal rejenerasyonu oluşturmaya yönelik çalışmalar yoğunlaşmıştır. Bariyer membran ve greft malzemelerinin kullanımı ile uygulanan rejeneratif cerrahi işlemler periodontal cep derinliğini azaltır, periodontal ligament formasyonunu destekler ve fonksiyonel olarak yeniden yapılanmasına yardim eder (3).

Rejeneratif periodontal tedavinin başarısı için anahtar faktör, rejenerasyon için gerekli moleküler ve hücresel olayların anlaşılmasıdır. Yapılan araştırmalar sonucu periodontal dokuların gelişimi ve periodontal rejenerasyonun oluşumu sırasında benzer olayların gerçekleştiği gözlenmiştir. Gelişim ve rejenerasyon süreçlerinin ikisinde de hücrelerde migrasyon, ataşman, proliferasyon, biyosentez ve farklılaşma gözlenmektedir. $\mathrm{Bu}$ olayların oluşumunu tetikleyen biyolojik mediatörlerde aynıdır. Periodonsiyumun gelişiminde rol alan molekül ve proteinler periodontal tamir ve rejenerasyon sirasında da etkili olmaktadır $(4,5)$. Cerrahi işlemin ardından, pıhtı oluşumu sert ve yumuşak dokuların iyileşme ve rejenerasyonunu başlatır. Dişin gelişimi sırasında, spesifik büyüme faktörleri ve morfojenler, epiteliyal ve mezenşimal kaynaklı hücreleri farklılaşma için tetiklemektedir. Periodontal dokuların gelişimi ve rejenerasyonu için kritik olan faktör, uygun hücrelerin gelişim ve tamir alanına çekilmesidir (6).
Periodontal dokularda bulunan büyüme faktörleri şunlardır: Trombosit kaynaklı büyüme faktörü (PDGF), insülin benzeri büyüme faktörü (IGF), transforme edici büyüme faktörü beta (TGF- $\beta$ ), asidik ve bazik fibroblast büyüme faktörü (aFGF, bFGF), vasküler endoteliyal büyüme faktörü (VEGF), epidermal büyüme faktörü (EGF), sement kaynaklı büyüme faktörü (CGF), paratiroid hormonla ilişkili protein (PTHrP) ve kemik morfogenetik proteinler (BMP) (7).

\section{Büyüme Faktörlerinden En Etkin Olanları:}

Trombosit kaynaklı büyüme faktörü (PDGF): $\mathrm{Bu}$ madde hemen hemen tüm yara iyileşmelerinde güçlü bir düzenleyici ve koruyucu etki göstermektedir. Başlıca fonksiyonu bağ doku ve kemik iyileşme hücrelerinin mitogenezisini uyarmaktır $(8,9)$. Osteoprogenitor hücrelerin farklılaşmasını ve kemik kollajeninin sentezini uyarır (10). Aynı zamanda osteoklast sayısını arttırarak kemik rezorbsiyonunu uyarır ve kemiğin yeniden şekillenmesini hızlandırır $(9,11)$. TGF ayrıca yeni kapillarların gelişmesine sebep olan (angiogenesis) endoteliyal hücrelerin reaksiyonunan yol açar (9).

TGF- $\beta$ (Transforme Edici büyüme faktörü- $\beta$ ): $\mathrm{Bu}$ madde çeşitli hücre tiplerinin çoğalma ve farklılaşmasını düzenler. Trombositlerde, TGF $\beta 1$ ve TGFß2 olmak üzere iki formda bulunur (12). Osteogeneziste osteoblastların proliferasyonunu uyararak kemik kollejen sentezini direkt olarak etkiler $(9,11)$.

VEGF (Vasküler Endotelyal Büyüme Faktörü): EBF, hücrelerin farklılaşması ve yeniden epitelizasyonu, anjiogenezisi ile kollejenaz aktivitelerinden sorumludur $(9,11)$.

IGF (Insulin Büyüme Faktörü): IGF yara iyileşmesinde osteoblastların büyüme ve farklılaşmasının uyarılmasında önemli bir yere sahiptir. Kondroblastik büyüme ve metabolizmanın düzenlenmesini sağlar $(9,11)$. 
Trombosit Büyüme Faktörlerinin yara iyileșmesindeki bașlıca rolleri așağıda sıralanmıștır:

- Anjiogenezisteki artış sayesinde doku vaskularizasyonunu arttırmaları $(8,9)$.

- Monositler, makrofajlar ve fibroblastlar için kemotaktik özelliklerinin olması $(8,9)$.

- Kollajen sentezini arttırmaları $(8,9)$.

- Epitel ve granulasyon doku üretim oranını arttırmaları $(8,9)$.

- Osteogenezisi hızlandırmaları $(8,9)$.

- Yüksek lökosit konsantrasyonuyla antimikrobiyal etki göstermeleri, yarada hemostaz ve lenfatik tampon görevi yaparak postoperatif sızıntıları önlemeleri ve ağrıyı azaltmaları (13).

- Duramaterle ilgili uygulamalarda sızdırmaz bir tampon görevi görmeleri (13).
- Oto/allogreft kemik partikülleriyle karıştırıldıklarında dokunun yeniden yapılanmasında macun benzeri ideal bir form oluşturmaları (13).

- Acil cerrahide hemostatik ilaç olarak biyolojik uygunluk göstermeleri, etkili ve güvenilir olmalarıdır (13).

- Doğal yara iyileşmesinde temel rol oynayan büyüme faktörü kompleksinin ana kaynağı trombositlerdir. Trombositler sadece piht1 şekillendirerek lokal kan ve lenf kaybını önlemekle kalmaz aynı zamanda yara iyileşmesini başlatan büyüme faktörlerini ve sitokinleri içerir (14).

Trombositlerin kandaki normal konsantrasyonu milimetreküpte 150.000-350.000'dir. Çapları 1.5-3.0 $\mu \mathrm{m}$ arasında değişen trombositlerin dolaşımdaki ömrü 8-10 gündür (15).

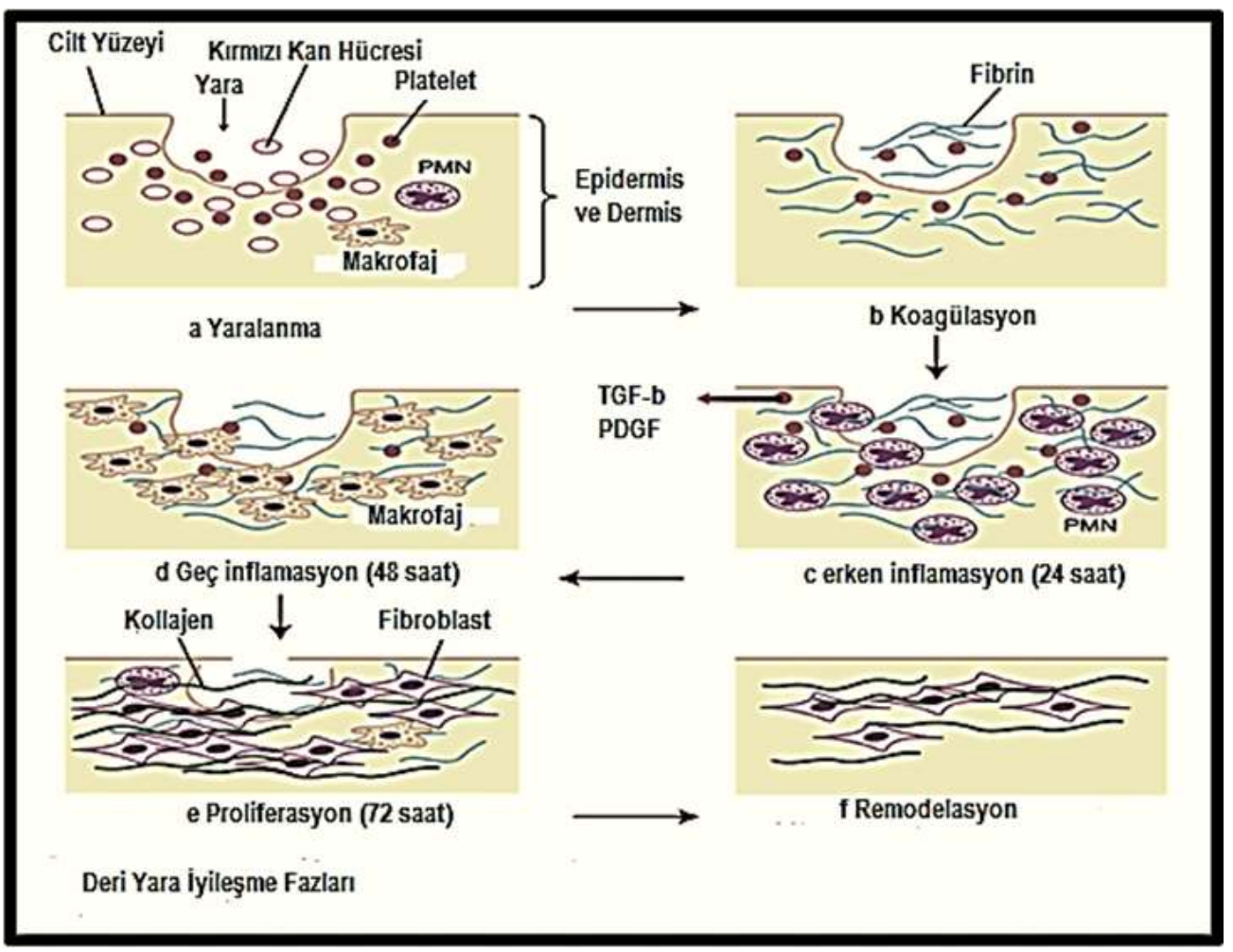

Şekil 1 
Tablo 1. Trombosit granülleri ve içerikeri

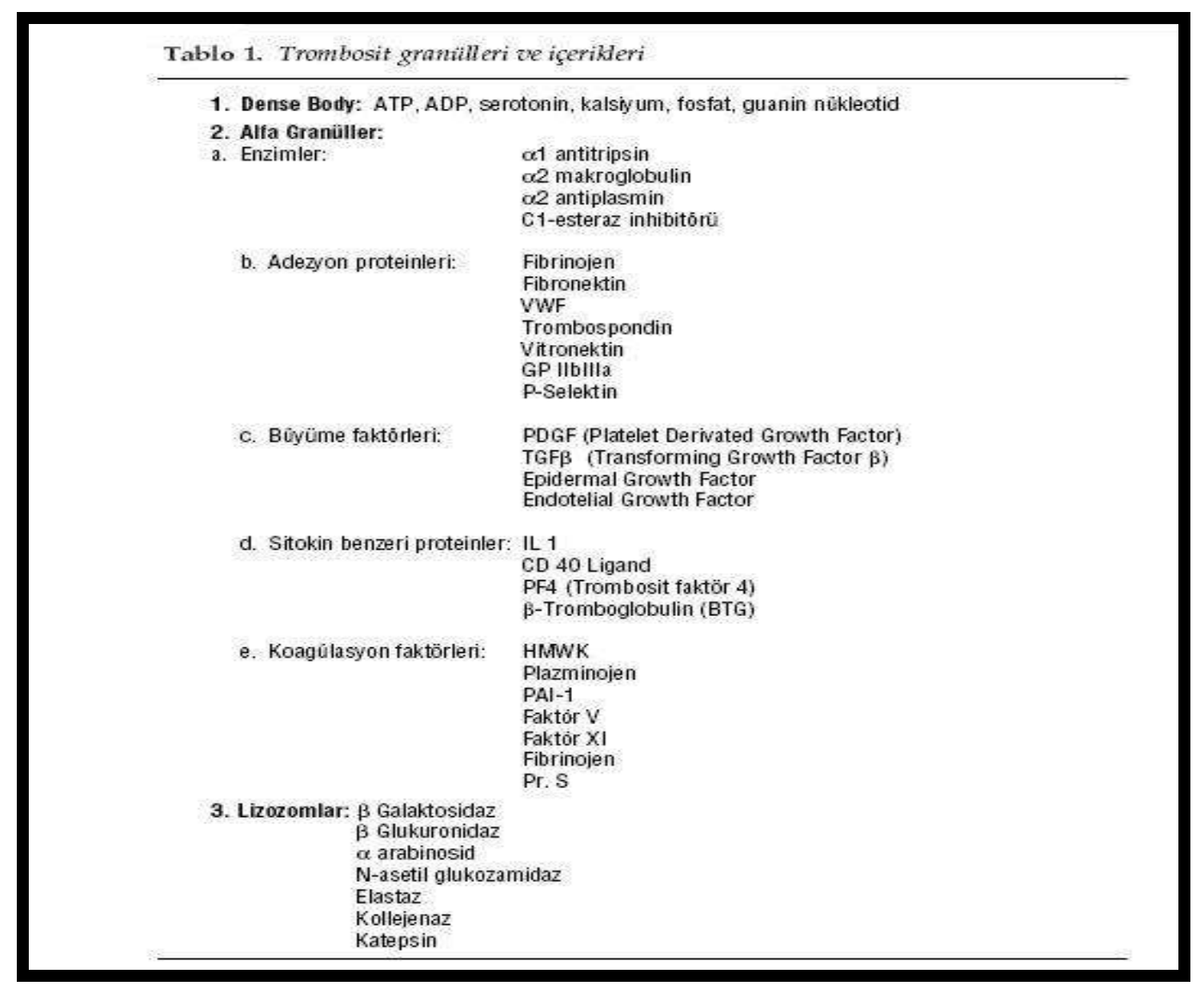

Şekil 2

\section{Trombositten Zengin Plazma (PRP)}

Son yıllarda geliştirilen trombositten zengin plazma uygulamaları, doğal pıhtıdaki eritrosit/trombosit oranını tersine çevirerek, büyüme faktörlerinin konsantre halde cerrahi bölgesine uygulanmasını sağlamakta, yara iyileşmesini ve rejenerasyonu hizlandırmaktadır $(16,17)$. Normal bir yaralanma ya da cerrahi sonrasında alanda yaklaşı 232.000 trombosit bulunmasına karşıllk, PRP uygulamasından sonra bu sayı 785.000'e çıkmaktadır. Yani PRP uygulamasıyla bölgedeki trombosit sayıs1 \%338 arttrrılmaktadır (17). $\mathrm{Bu}$ nedenle periodontal rejenerasyonu arttırmak için kemik greftleri ile birlikte ya da tek başına PRP uygulamaları umut vaat edici olabilir. Trombositten zengin plazma hem yumuşak hem de sert dokunun klinik olarak hızlı bir şekilde iyileşmesini sağladığı için kısa sürede popüler olmuştur $(10,18)$.
Kemik rejenerasyonu, yaralanmanın ardından fibrin ağı oluştuktan sonra, degranüle olan trombositlerden PDGF ve TGF- $\beta$ salınımı ile başlar. (19) PDGF kemik iliği kök hücrelerinde mitogenezi ve endosteal osteoblastların sayıları artarak greft alanına göçünü stimüle eder. Endotelial hücre mitozunu indükleyerek, greft alanında öncü kapiller hücrelerin anjiogenezini başlatır. TGF- $\beta$ ise; fibroblast ve preosteoblastları mitoz için aktive ederek sayıca artışlarını sağlar ve farklılaşarak matür osteoblastlara dönüşmelerini indükler. TGF- $\beta$ salınımının devam etmesi kapiller gelişimi desteklemek üzere, osteoblastları etkileyerek kemik matriksi oluşumunu ve fibroblastları etkileyerek kollajen matriks oluşumunu artırır. $\mathrm{Bu}$ aktiviteler yaranın kapatılmasının hemen ardından gerçekleşir. 3 . günde kapiller greft içine penetre olmaya başlar ve 14 ile 17. günde greftin tamamen kapiller ağı oluşmuş 
olur. Çok sayıda hücre iyileşirken ve rejenere olurken gereken enerjiyi en aza indirmek için bu sürecin ilk aşamaları oldukça hızlı ilerler. Büyüme faktörleri bu hücrelerin hızla sayıca artmasını ve aktivite kazanmalarını sağlar (20). Trombositlerin ömrü 5 günden azdır ve bu süre içerdiği büyüme faktörlerinin işlevsellik sürecini direkt etkilemektedir. İyileşme ve kemik rejenerasyon aktivitesi iki mekanizma ile devam eder. İlki kemik iliği kök hücrelerinin aktivasyonu ile osteoblastlardan TGF- $\beta$ salınımıdır. İkinci ve daha sık görülen mekanizma ise; makrofajların kemotaksis ile alana gelip trombositlerle yer değiştirmesi ve 3. günden sonra büyüme faktörlerinin ana kaynağı olmasıdır (21,22). Makrofajlar PDGF'nin etkisi ile grefte tutunurlar, greft ile sağlıklı komşu doku arasında oksijen değişimi olur. PDGF'nin etkisi azalarak yerini makrofaj kaynaklı büyüme faktörlerine ve anjiojenik faktörlere bırakır. Bu büyüme faktörleri PDGF ile aynı etkilere sahiptir, aradaki tek fark trombositlerden değil, makrofajlardan salınmalarıdır. Kemik iliği kök hücreleri, otokrin bir etki ile kendi kendilerini stimüle ederek, TGF- $\beta$ salgilamaya devam eder. 4 . haftada revaskülarize olan greft, makrofaj aktivitesi için gerekli olan oksijen değişimine son verir. Makrofajlar alandan ayrılırken, olgunlaşmamış osteoid doku oluşmuştur. Kemik greftinin havers sistemini içeren olgun lameller kemiğe dönüşmesinde ise; kemik morfogenik proteinleri (BMP) olarak adlandırılan ve osteoid dokudan salınan proteinler rol oynamaktadır. Yeni oluşan kemik matriksinden salınan BMP'ler komşu kemik kök hücrelerinin sayıca artarak osteoblasta farklılaşmasını ve aktif olarak kemik matriks sentezini ve mineralizasyonunu sağlar (20).

\section{Yara İyileşmesinde PRP Kullanımının Tarihi:}

Fibrinojenin bir doku yapıştırıcı olarak kullanımıyla ilgili ilk denemeler 1940'lı yıllara dayanmaktadır. Koagülasyon faktörlerinin izolasyonu ve konsantrasyonu ile ilgili tekniklerin ilerlemesiyle 1970'lerde fibrin yapıştırıcıyla yapılan çalışmalar hız kazanmıştır. 1972'de periferal bir sinirin fibrin yapıştırıcı ile başarılı bir şekilde onarıldı̆̆ bildirilmektedir (18). "Otolog Trombositten Zengin Plazma" (Trombosit jel) 1970'lerin başında çok bileşimli kan ürünlerinin bir yan ürünü olarak geliştirilmiştir. Tekniklerin ve kullanılan ekipmanların hızlı bir şekilde gelişmesiyle 1990'larda kandaki çeşitli elementlerin doğal iyileşmenin bir parçası olduğu ve konsantre bir şekilde yaraya uygulandığında iyileşmeyi hızlandırdığı keşfedilmiştir (10).

\section{PRP Elde Ediliși:}

Literatürde birbirinden farklı tekniklerden bahsedilmesine rağmen PRP elde etmek için izlenmesi gereken yol aynıdır. Bunun için öncelikle venöz kan elde edilir. Damar dışına çıkan kanın pıhtılaşmasını engellemek için antikoagülan bir madde ile karıştırılmalıdır. $\mathrm{Bu}$ karışım uygulanan tekniğin gerektirdiği sürede kanın pıhtılaşmasını engeller. Elde edilen karışım belli bir merkezkaç kuvvetine maruz bırakılır. Buradaki amaç kanda bulunan şekilli elemanların ağırlıklarına göre çökmesini sağlayarak istenen kan fraksiyonunu (trombosit) belirli bir bölgede toplamaktır. Antikoagülan ile karıştırılmış ve tüpe yerleştirilmiş kan ilk santrifüj sonrasında iki kısma ayrılmış gibi görünmektedir.

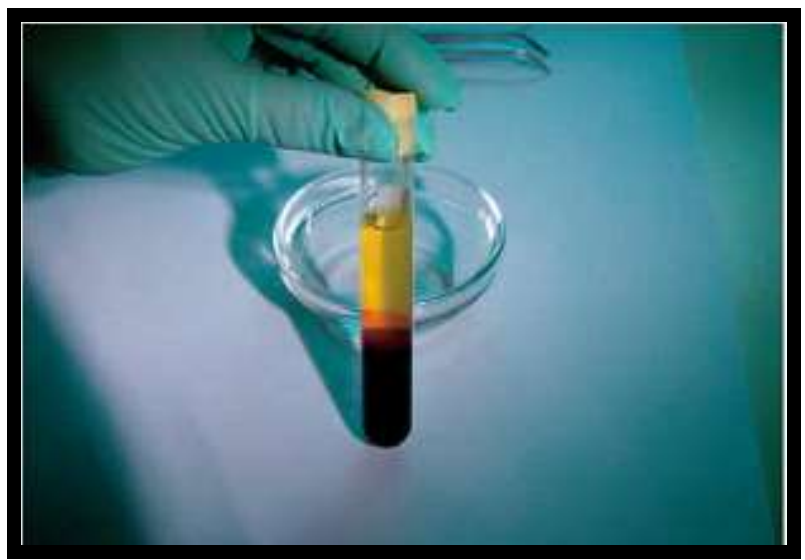

Şekil 3

Ağırlıklarından dolayı eritrositler tüpün alt kısmında birikirken, üst kısımda sarı renkli plazma görülür. Plazma kısmının eritrositlere yakın olan alt bölümünde 
ise trombositler yoğunlaşır (buffy coat). Yapılan incelemelerde yeni sentezlenen trombositlerin, eritrositlerin oluşturduğu fraksiyonun üst kısmında yoğun olarak bulunduğu anlaşılmıştır. Bu nedenle tüm plazma içeriğinin yanı sıra eritrositlerin bulunduğu kısmın üzerinden bir miktar alınması da önerilmektedir.

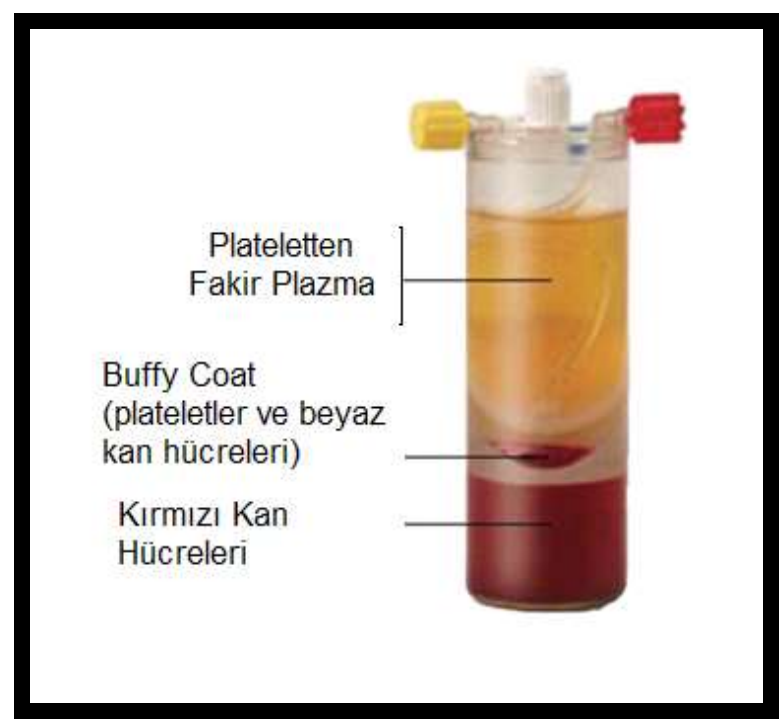

Şekil 4

Sonuçta elde edilen ve plazma ile az miktarda eritrositten oluşan karışım bir kez daha santrifüj edilerek trombosit fraksiyonunun tüpün alt kısmında toplanması sağlanır. $\mathrm{Bu}$ aşamadan sonra trombosit sayısı artmış olan plazma elde edilmiş olur ve antikoagülan etkinin ortadan kalkması için $\mathrm{CaCl} 2$, trombositleri aktive edip granül içeriklerini boşaltmalarını sağlamak için ise trombin ya da hastanın kendi kanı ile karıştırılır. Sonuçta normal trombosit sayısından daha yoğun miktarda trombosit içeren ve bu trombositlerin aktive olması sonucu granüllerindeki büyüme faktörlerinin ortama salındığ edilmiş olur (23).

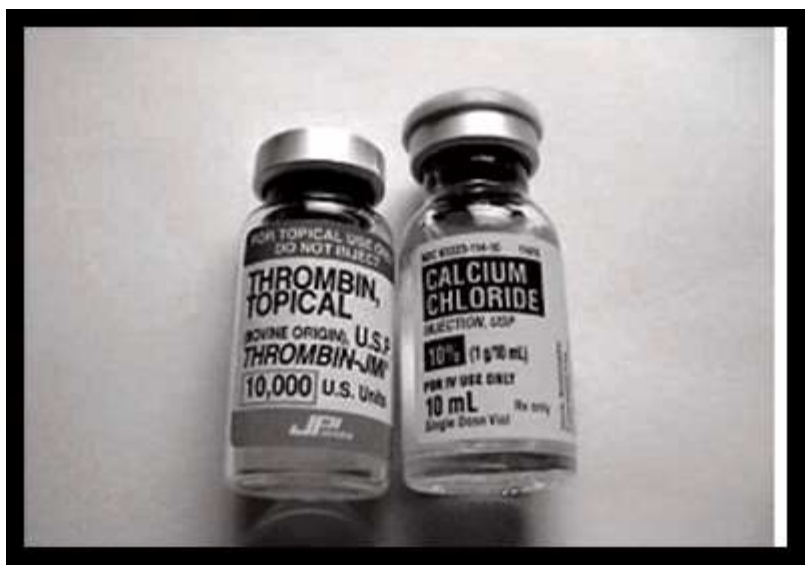

Şekil 5

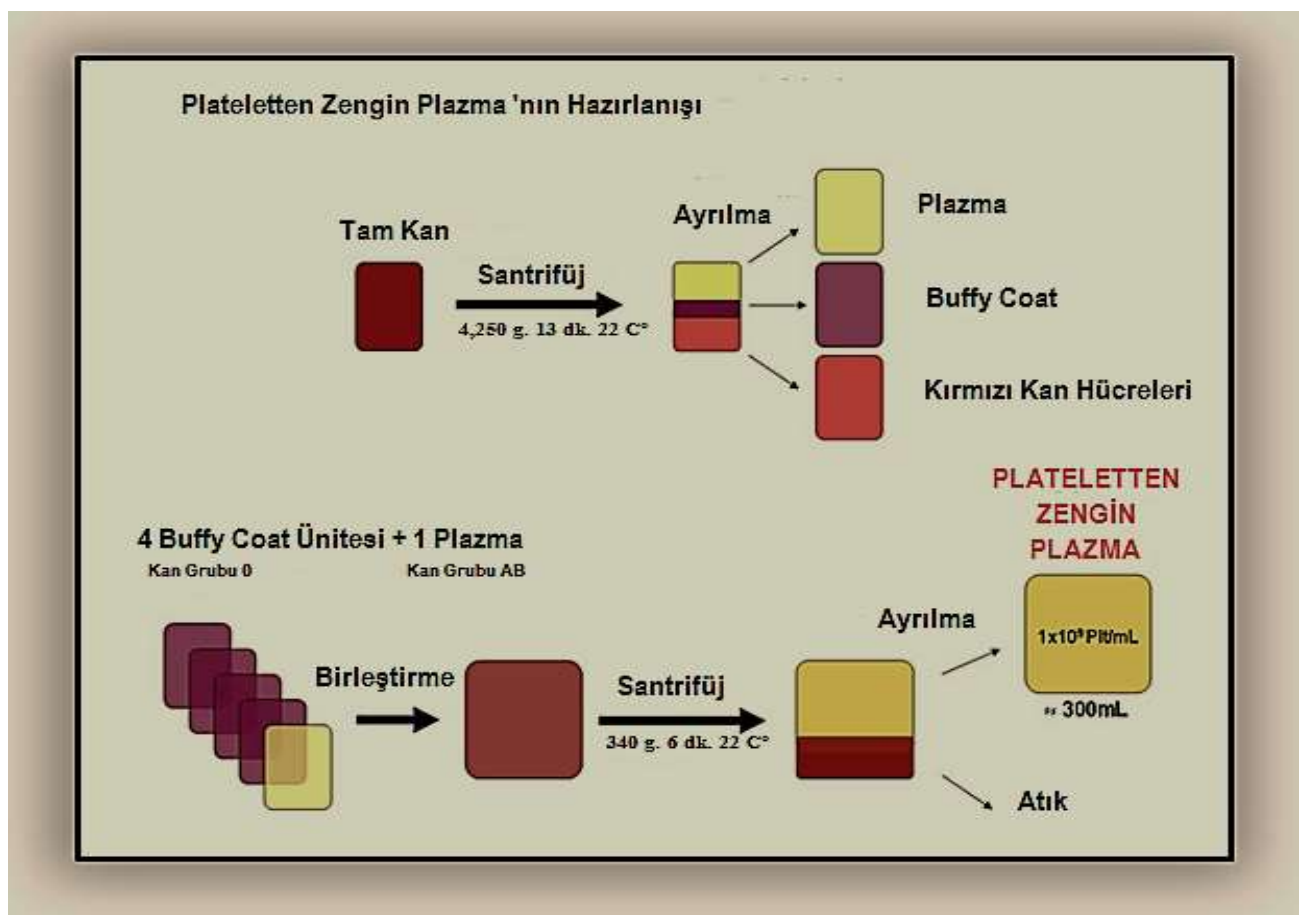

Şekil 6 


\section{PRP'nin Saklama ve Etki Süresi}

PRP içindeki PDGF ve TGF- $\beta$ 'nin venöz kan alımını takiben, 4 saat ile 3 gün arasında, hücre büyümesini stimüle edici etkilerinin giderek azaldığı bildirilmiştir (24). Trombositlerin agregasyon cevaplarında da belirgin düşüş rapor edilmiştir (25). Materyal kontaminasyonu ve hastalık taşıyıcılığı risklerini düşük tutmak açısından da PRP'nin hazırlandıktan sonra en kısa zamanda (25), özellikle ilk 6 saat içerisinde kullanımı önerilmiştir (26). Trombositlerin degranülasyonu ve büyüme faktörleri salınımının ilk 35 günde olduğu, bu nedenle PRP aktivitesinin de 7-10 gün olduğu ileri sürülmüştür (27). Trombositlerin ve trombosit kaynaklı büyüme faktörlerinin direkt etkilerinin ilk 5-6 günden sonra yavaş yavaş kaybolacağ1, ancak aktif osteoblastların ömrünün yaklaşık 3 ay (28) olduğu göz önüne alındığında, kemik rejenerasyonunun hızlanmış bir şekilde devam edeceği öne sürülmüştür $(29,30)$.

\section{PRP ile İlgili Çalışmalar}

1. In vitro çalışmalar

Yapılan in vitro çalışmalar PRP'nin alveoler kemik, dişeti, periodontal ligament ve periost kaynaklı hücrelerin proliferasyonunu stimüle ettiğini göstermektedir (31-33).

2. In vivo çalışmalar

PRP kullanımı ile ilgili in vivo çalışmalar deneysel mandibula, calvaria, implant çevresi defektleri ile sinüs ve soket ogmentasyonu ve implantla birlikte uygulama ile ilgili işlemlerini içermektedir $(34,35)$. Yapılan çalışmalar incelendiğinde PRP'nin kemik oluşum miktarı ve kalitesine olumlu katkı yaptığını gösteren çalışmaların yanı sıra herhangi bir pozitif etkisinin bulunmadığını gösteren de çok sayıda çalışma görülmektedir. $\mathrm{Bu}$ farklılık in vivo çalışmalarda kullanılacak hayvan, uygulama yöntemi, uygulama sonrası bekleme süresi ve defekt tip ve boyutları gibi henüz standardize edilememiş farklı parametrelerin etkisine bağlanabilir.

\section{Klinik çalışmalar}

Dişhekimliğinde PRP'nin; kret, sinus ve soket augmentasyonu, alveoler kleftlerin cerrahi tedavisi, implant cerrahisi ile ilgili gerekli durumlar, mandibula rekonstrüksiyonu, periapikal cerrahi, planlanmış replantasyon ve periodontal kemik defektlerinin tedavisi gibi alanlarda kullanıldığı görülmektedir (3639). PRP uygulamasının periodontal plastik cerrahide kullanılması ile ilgili çalışmalara bakıldığında yakın dönemde yayınlanmış üç adet literatür dikkat çekmektedir.

2004 yllinda Griffin \& Cheung trombosit greft konsantresi ismini verdikleri PRP/kollajen sünger taşıyıcı kombinasyonunu KPF ile beraber çekilme tedavisinde uygulamışlar ve klinik olarak başarılı sonuçlar almışlardır (40).

Aynı yıl yine aynı iki araştırıcı bu kez trombosit greft konsantresini 15 adet bilateral, Miller I ve II dişeti çekilmesine sahip bireyde BDG uygulaması ile karşılaştırmışlar ve 8. ayda BDG ile benzer sonuçlar elde etmişlerdir. Araştırıcılar trombosit greft konsantresi uygulanan grupta alınan sonuçların diğer gruba göre daha estetik olduğunu özellikle vurgulamışlardır (41).

Son çalışmada ise BDG, PRP ile kombine olarak kök kapatılması için uygulanmış ve yalnız BDG uygulanan grupla 6. ayda karşılaştırılmıştır. Elde edilen sonuçlar PRP'nin kök kapanmasında BDG'ye ilave katkısı olmadığını saptamıştır. Ancak PRP/BDG kombinasyonunun uygulandığı grupta daha fazla keratinize doku kazancı ve daha kısa sürede yara iyileşmesi meydana gelmiştir.

\section{Trombositten Zengin Fibrin (PRF):}

2. nesil trombosit çözeltisi. PRF in kullanımındaki ana amaç ve beklenti sert doku ve yumuşak dokudaki iyileşme hızını ve potansiyelini artırmaktır. PRF, ilk defa 2001 yılında Fransiz Joseph Chouckroun tarafından tanımlanmıştır. Daha öncesinden beri 
kullanılan, PRP olarak adlandırılan "Trombositten zengin plazma" preparatına göre birçok avantajı vardır.

\section{Özellikleri ve Üstünlükleri:}

Choukroun'in trombositten zengin fibrini (PRF) kan kaynaklı ürünlerin son geliştirilen tipidir. $\mathrm{Bu}$ yöntemle kan herhangi bir antikuagülana ihtiyaç duyulmadan alınır ve hemen sonrasında bir kez santrifüj edilir. Choukroun'in PRF'sinde doğal pıhtılaşma süreci oluşur ve kanın herhangi bir biyokimyasal modifikasyonuna ihtiyaç duyulmadan lökositten ve trombositten zengin fibrin pıhtının kolay bir şekilde elde edilmesine izin verilir. Bu teknik günümüze kadar geliştirilen en kolay ve ucuz kan kaynaklı ürün elde etme yöntemi olarak dikkati çekmektedir (42).

Fibrin matriksi yoğun bir şekilde trombosit, lökosit ve sitokin içermektedir. Matriksin fizyolojik rezorpsiyonu sırasında devamlı ve yavaş bir şekilde sitokin salınımı gerçekleşir. $\mathrm{Bu}$ sitokin salınımı sayesinde yara bölgesindeki enflamatuvar olaylar düzenlenir (43-45).

PRF antikoagülan tedavi gören hastalarda içeriğindeki trombospondin-1 ile koagülasyonu arttırarak yara kapanmasına katkı sağlar ayrıca özellikle diabet veya immunsupresyon durumundaki iyileşmenin geciktiği hastalarda yara ve çekim bölgelerinde pıhtı gibi görev alarak vaskülarizasyonu ve yeni doku oluşumunu arttırır. Böylece dry soket gibi komplikasyonlardanda kaçınılmış olur $(46,47)$.

PRF yara bölgesinde fazla sayıda lökosit içeren yoğun bir fibrin iskelet oluşturarak hem yara iyileşmesini etkiler, hem osteokondüktif bir etki oluşturur, hem de 7 günden fazla süren yavaş bir şekilde büyüme faktörlerinin salınımını yaparak bölgedeki doku yenilenmesini arttırıcı ve hızlandırıcı etki sağlar $(48,49)$.

PRF membran yoğun fibrin içeriği sayesinde PRP protokolüne nazaran daha elastik ve sağlam bir membran yapısındadır (50). Bu özelliği sayesinde daha kolay sütüre edilebilir $(51,52)$.
Klinikte PRF Elde Etmek İçin Gerekli Ekipmanlar:

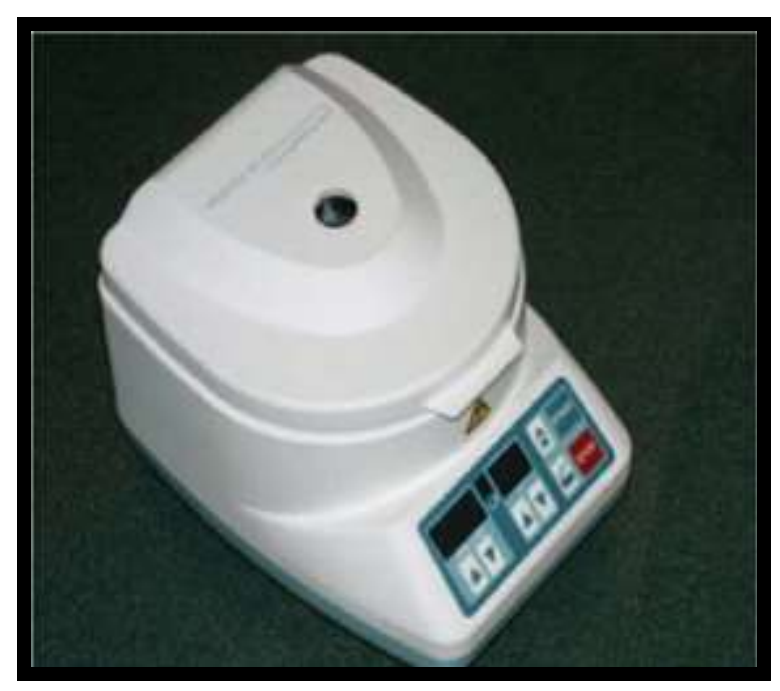

Şekil 7

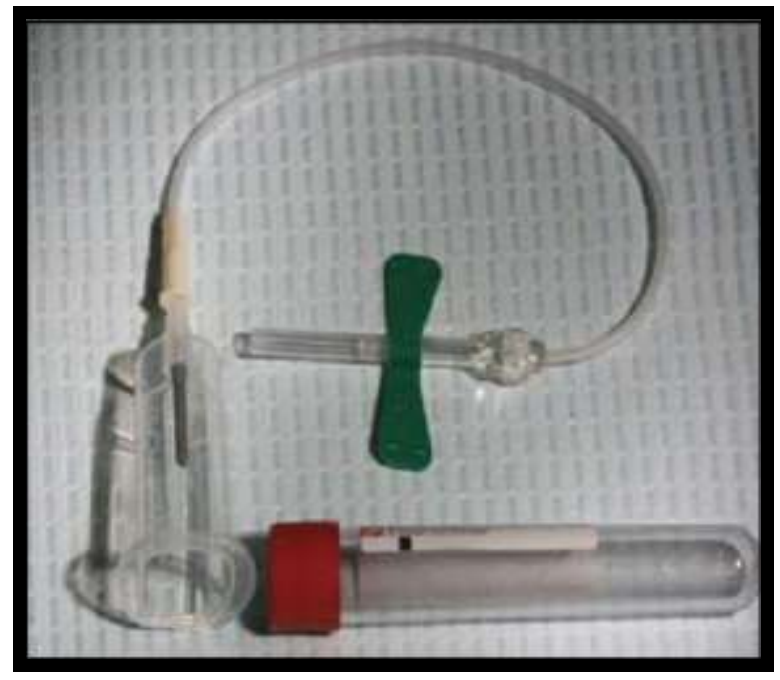

Şekil 8

\section{PRF Mekanizması:}

Fibrin; Kanda çözünmüş olarak bulunan fibrinojen, pıhtılaşma sırasında, trombin enzimi etkisiyle katı, polimer yapılı, çözünmez bir protein olan ve ağ şeklinde liflerle yarayı saran fibrine dönüşüp kanı koyultur. 


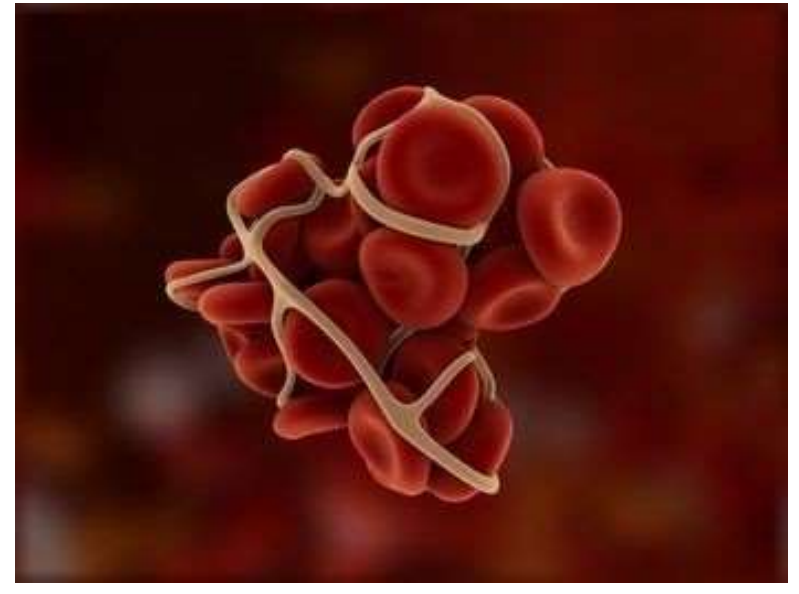

Şekil 9

PRF de $10 \mathrm{ml}$ test tüpüne yeter miktarda kan alınır ve $12 \mathrm{dk}$ 2,700 rpm de santrifüj edilir (54).Tüp içerisinde antikoagülan olmadığından tüp duvarları ile temas halinde olan kanda trombositlerin birkaç dakika içinde aktivasyonu (Şekil 10) sonucu pıhtılaşma meydana gelecektir. Fibrinojen tüpün üst kesiminde yoğunlaşmadan önce, dolaşımdaki trombin tarafından fibrine dönüştürülür.

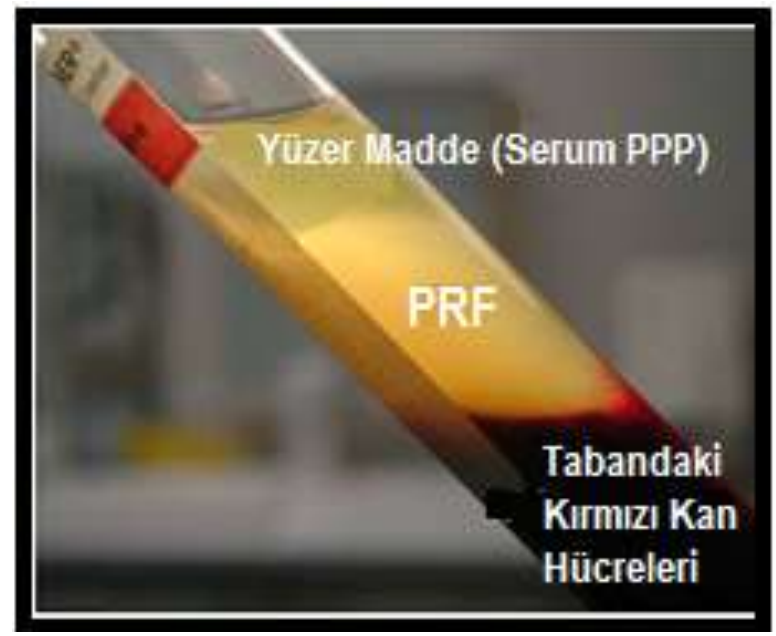

Şekil 10

Üstte asellüler plazma ve altta kırmızı cisimciklerin arasında tüp ortasında fibrin bir pihtı elde edilir. Trombositler teorik olarak tek parça halinde topluca fibrin kafese hapsolmuş olarak bulunur.

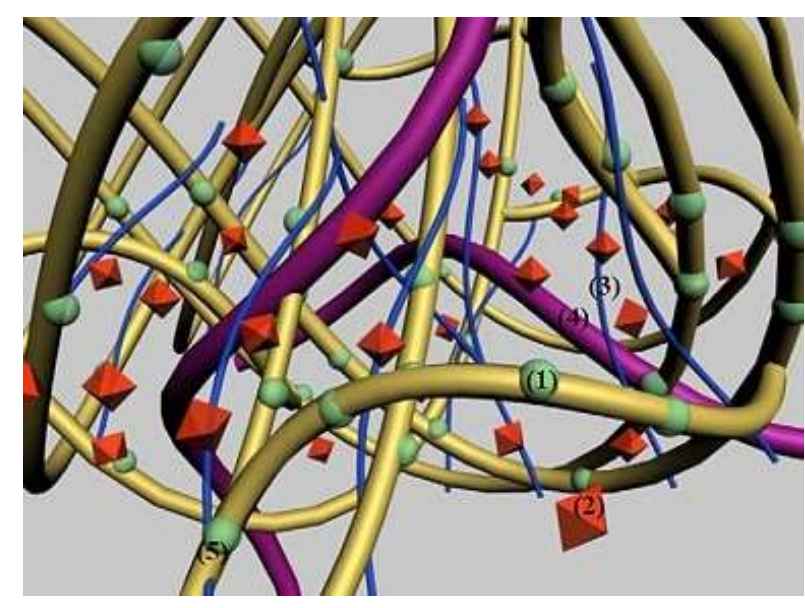

\section{Şekil 11}

Bu pıhtı tüpten çıkarılır ve bağlı bulunduğu kırmızı kan hücreleri kazınıp, atılır.

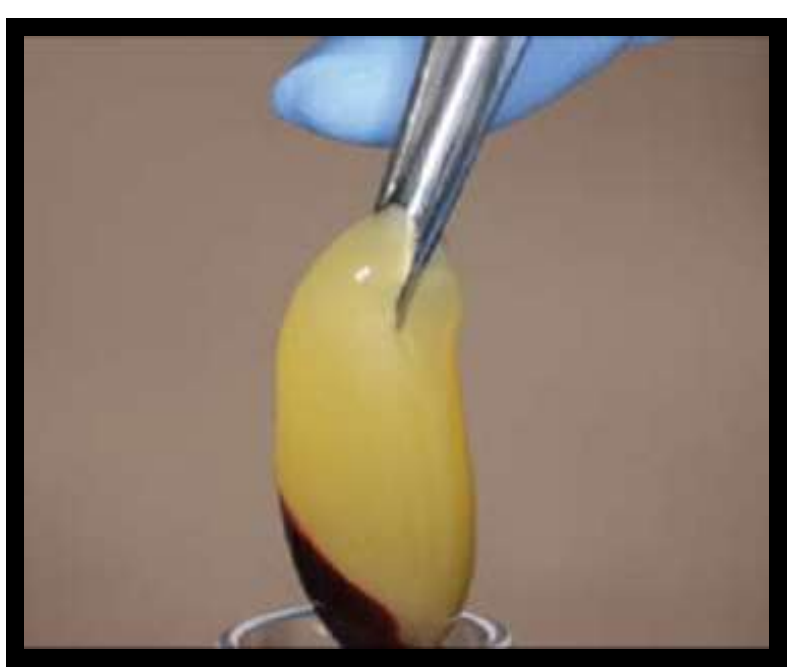

Şekil 12

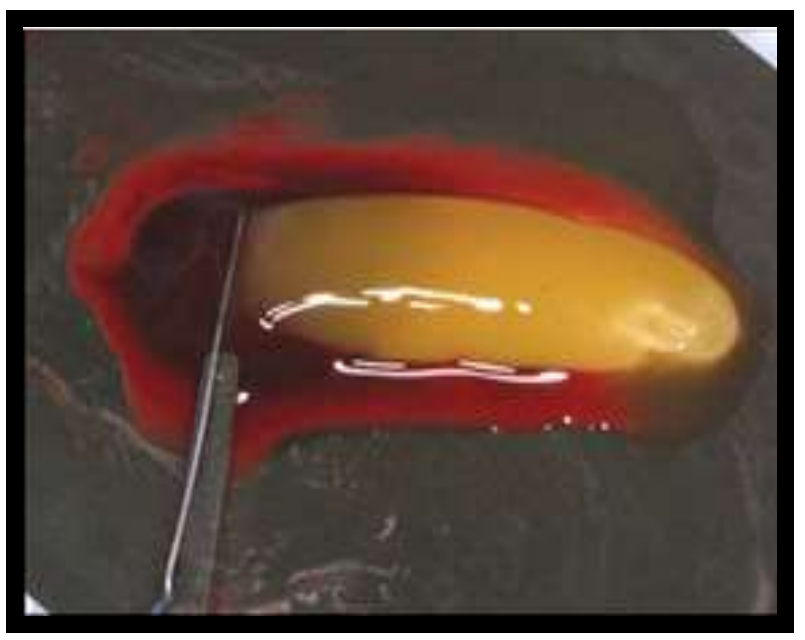

Şekil 13 
Ayrıca elde ettiğimiz PRF leri PRF Box kullanarak homojen ölçülerde membran haline de getirebiliriz.

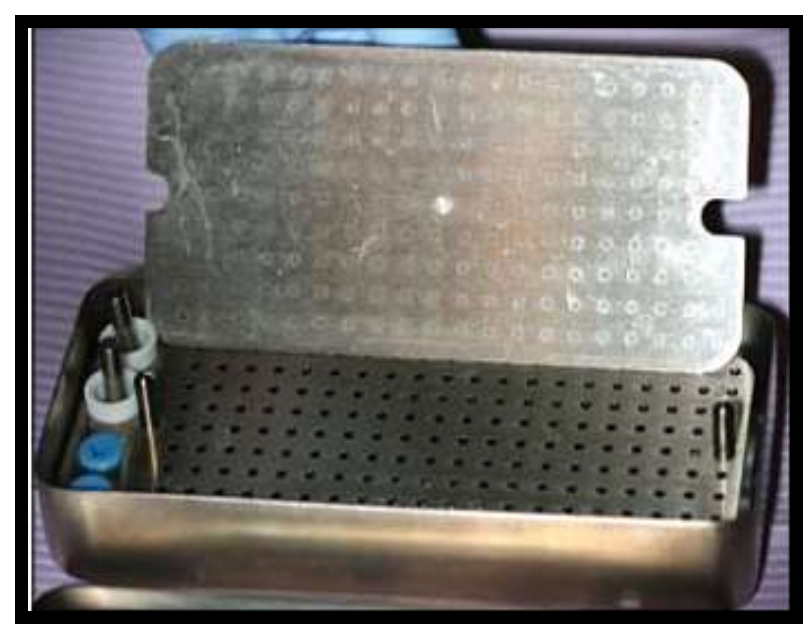

Şekil 14

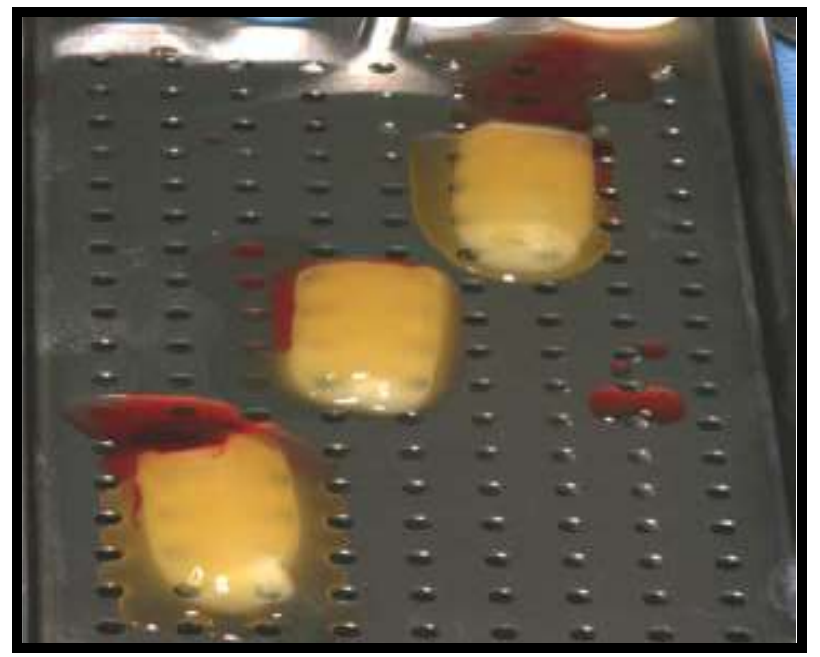

\section{KAYNAKLAR}

1. Garret S. Periodontal regeneration around natural teeth. Ann Periodontol. 1996; 2: 621-66.

2. Rutherford RB, Ryan ME, Kennedy JE, Tucker MM, Charette ME. Platelet-derived growth factor and dexamethasone combined with a collagen matrix induce regeneration of periodontium in monkeys. J Clin Periodontol. 1993; 20: 537-44.

3. Shallhorn RG, McClain PK. Combined osseous composite grafting, root conditioning, and guided tissue regeneration. Int $\mathrm{J}$ Periodontics Restorative Dent. 1988; 8: 8-31.
Şekil 15

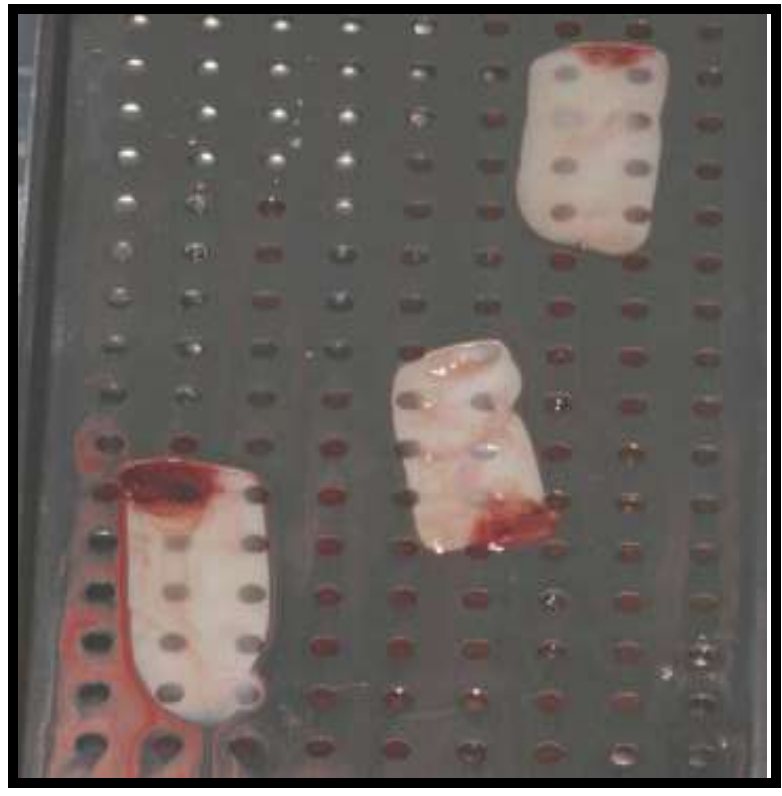

Şekil 16

$\mathrm{Bu}$ tekniğin başarısı tamamen kan toplama hızı ve alınan kanın santrifüje transferine bağlıdır.

PRF elde etmek için hızlı transfer klinik olarak kullanılabilir tek yoldur. Kan toplamak ve santrifüjü başlatmak için uzun süre geçerse, başarısızlık ortaya çıkar: fibrin, tüp içinde dağınık şekilde polimerize olur ve tutarlılığı olmayan sadece küçük bir kan pıhtısı elde edilir (55).

4. Osborn JW, Price DG. An autoradiographic study of periodontal development in the mouse. J Dent Res. 1988; 67: 455-61.

5. McCauley LK, Somerman MJ. Biologic modifiers in periodontal regeneration. Dent Clin of North Amer (Part I). 1998: 361-87.

6. Lang NP. Focus on intrabony defects-conservative therapy. Periodontol. 2000; 22: 51-8.

7. Anusakthien O, Giannobile WV. Growth factor delivery to re-engineer periodontal tissues. Current Pharmaceutical Biotechnology. 2002; 3: 129-39. 
8. Schmitz JP, Hollinger JO. The biology of plateletrich plasma. Letters to the Editor. J Oral Maxillofac Surg. 2001; 59: 1119-21.

9. Sanchez AR, Sheridan PJ, Kupp LI. Is plateletrich plasma the perfect enhancement factor? A current review. The International J Oral \& Maxillofacial Implants. 2003; 18: 93-103.

10. Tambini K. Platelet Rich Plasma. UIC Dept OMFS Grand Rounds June 2001.

11. Grageda E. PlateletRich Plasma and bone graft materials: A review and a standardized research protocol. Implant Dentistry. 2004; 13(4): 301-9.

12. Man D, Plosker H, WinlandBrown JE. The use of autologous PlateletRich Plasma (Platelet Gel) and autologous PlateletPoor Plasma (Fibrin Glue) in cosmetic surgery. Plastic and Reconstructive Surgery. 2001; 107(1): 229-37.

13. Buza PW. Case studies Platelet Rich Plasma (Thrombograft PRP). Spacecoast Aromedical Institute. Erişim tarihi:12.05 2005. Erişim: http:/www.heartpumpur.com/prp_clinical_a pplications.htm.

14. Carter CA, Jolly DG, Worden Sr CE, Hendren DG, Kane CJM. PlateletRich Plasma gel promotes differentiation and regeneration during equine wound healing. Experimental and Molecular Pathology. 2003; 74: 244-55.

15. Ulutin O. The platelets. İstanbul 1976; 217-253. İ.Ü. Cerrahpaşa Tıp Fakültesi Sürekli Tıp Eğitimi Etkinlikleri Kanama ve Tromboza Eğilim Sempozyum Dizisi No: 36, 2003: 37-60.

16. Carlson NE, Roach RB Jr. Platelet-rich plasma: clinical applications in dentistry. J Am Dent Assoc. 2002; 133: 1383-6.

17. Tözüm TF, Demiralp B. Platelet-rich plasma: A promising innovation in dentistry. J Can Dent Assoc. 2003; 69: 664-664h.
18. Eppley BLMD, Woodell JE, Higgins JBS. Platelet quantification and growth factor analysis from PlateletRich Plasma: Implications for wound healing. Plastic and Reconstructive Surgery. 2004; 114(6): 1502-8.

19. Yu X, Hsieh SC, Bao W, Graves DT. Temporal expression of PDGF receptors and PDGF regulatory effects on osteoblastic cells in mineralizing cultures. Am J Physiol. 1997; 272(5Pt1): C1709-16.

20. Marx RE, Carlson ER, Eichstaed RM, Schimmele SR, Strauss JE, Georgeff KR. Platelet-rich plasma: growth factor enhancement for bone grafts. Oral Surg Oral Med Oral Pathol Radiol Endod. 1998; 85: 638-46.

21. Pierce GF, Tarpley J, Yanagihara D, Deuel TF. PDGF-BB, TGF-B1, and basic FGF in dermal wound healing: neovessel and matrix formation and cessation of repair. Am J Pathol. 1992; 140:137588.

22. Mustoe TA, Purdy J, Gramates P, Deuel TF, Thomasen A, Pierce GF. Reversal of impaired wound healing in irradiated rats by platelet-derived growth factor-BB: requirement of an active bone marrow. Am J Surg. 1989; 158:345-50.

23. Keskiner İ, Trombositten zengin plazma ve otojen kemik grefti uygulamalarının köpeklerde fenestrasyon tipi defektlerde incelenmesi (Tez). 2007

24. Ferreira FC, Gomez MCC, Filho JS, Granjeiro JM, Simoes CMO, Magini RS. Platelet-rich plasma influence on human osteoblasts growth. Clin Oral Implants Res. 2005;16: 456-60.

25. Kocazeybek B, Arabaci U, Akdur H, Sezgic M, Erenturk S. Prospective evaluation of platelets prepared by single and random methods during 5 days of storage: aspects related to quality and quantity. Transfus Apher Sci. 2002; 26: 29-34. 
26. Kassolis JD, Rosen PS, Reynolds MA. Alveolar ridge and sinus augmentation utilizingplatelet rich plasma in combination with freeze-dired bone allograft: Case series. J. Periodontol. 2000; 71: 1654-61.

27. Raghoebar GM, Schortinghuis J, Liem RSB, Ruben JL, Van Der Wal JE, Vissink A. Does platelet-rich plasma promote remodeling of autologous bone grafts used for augmentation of the maxillary sinus floor? Clin Oral Implants Res. 2005; 16: 349-56.

28. Manolagas SC. Birth and death of bone cells: basic regulatory mechanisms and implications for the pathogenesis and treatment of osteoporosis. Endocr. Rev. 2000; 21(2): 115-37.

29. Jakse N, Tangl S, Gilli R, Berghold A, Lorenzoni M, Eskici A, Haas R, Pertl C. Influence of PRP on autogenous sinus grafts. An experimental study on sheep. Clin Oral Implants Res. 2003; 14(5): 578-83.

30. Marx RE, Carlson ER, Eichstaedt RM, Schimmele SR, Strauss JE, Georgeff KR. Platelet-Rich Plasma: Growth factor enhancement for bone grafts. Oral Surg Oral Med Oral Pathol Oral Radiol Endod. 1998; 85: 638-46.

31. Han J, Meng HX, Tang JM, Li SL, Tang Y, Chen ZB. The effect of different platelet-rich plasma concentrations on proliferation and differentiation of human periodontal ligament cells in vitro. Cell Proliferation. 2007; 40: 241-52.

32. Graziani F, Ivanovski S, Cei S, Ducci F, Tonetti M, Gabriele M. The in vitro effect of different PRP concentrations on osteoblasts and fibroblasts. Clinical Oral Implants Research. 2006; 17: 212-9.

33. Gruber R, Karreth F, Frommlet F, Fischer MB, Watzek G. Platelets are mitogenic for periosteumderived cells. Journal of Orthopaedic Research. 2003; 21: 941-8.
34. Kovacs K, Velich N, Huszar T, Fenyves B, Suba Z, Szabo G. Histomorphometric and densitometric evaluation of the effects of platelet-rich plasma on the remodeling of beta-tricalcium phosphate in beagle dogs. The Journal of Craniofacial Surgery. 2005; 16: 150-4.

35. You TM, Choi BH, Zhu SJ, Jung JH, Lee SH, Huh JY. Platelet-enriched fibrin glue and platelet-rich plasma in the repair of bone defects adjacent to titanium dental implants. The International Journal of Oral and Maxillofacial Implants. 2007; 22: 41722.

36. Marx RE, Carlson ER, Eichstaedt RM, Schimmele SR, Strauss JE, Georgeff KR. Platelet-rich plasma: Growth factor enhancement for bone grafts. Oral Surgery Oral Medicine Oral Pathology Oral Radiology and Endodontic. 1998; 85: 638-46.

37. Demir B, Sengun D, Berberoglu A. Clinical evaluation of platelet-rich plasma and bioactive glass in the treatment of intra-bony defects. Journal of Clinical Periodontology. 2007; 34: 709-15.

38. Simon D, Manuel S, Geetha V, Naik BR. Potential for osseous regeneration of platelet-rich plasma--a comparative study in mandibular third molar sockets. Indian Journal of Dental Research. 2004; 15: 133-6.

39. Rullo R, Festa VM, Guida L, Laino G. Bone grafting with platelet-rich plasma in alveolar cleft. Case report. Minerva Stomatologica. 2007; 56: 6371.

40. Griffin TJ, Cheung WS. Treatment of gingival recession with a platelet concentrate graft: a report of two cases. The International Journal of Periodontics and Restorative Dentistry. 2004; 24 : 589-95. 
41. Cheung WS, Griffin TJ. A comparative study of root coverage with connective tissue and platelet concentrate grafts: 8-month results. Journal of Periodontology. 2004; 75: 1678-87.

42. Dohan DM et al. Platelet-Rich Fibrin (TZF): second generation platelet concentrate. Part I: technological concepts and evolution. Oral Surg. Oral Med. Oral Pathol. Oral Radiol. Endod. 2006; 1: e37-44.

43. Dohan DM, de Peppo GM, Doglioli P, Sammartino G. Slow release of growth factors and thrombospondin-1 in Choukroun's platelet-rich fibrin (PRF): a gold Standard to achieve for all surgical platelet concentrates Technologies. Growth Factors. 2009; 27(1): 63-9.

44. Choukroun J, Diss A, Simonpieri A, et al. Plateletrich fibrin (PRF): A second-generation platelet concentrate. Part IV: Clinical effects on tissue healing. Oral Surg Oral Med Oral Pathol Oral Radiol Endod. 2006; 101: E56-60.

45. Dohan DM, Choukroun J, Diss A, Dohan SL, Dohan AJ, Mouhyi J, Gogly B. Platelet-rich fibrin (PRF): A second-generation platelet concentrate. Part II: Platelet-related biologic features. Oral Surg Oral Med Oral Pathol Oral Radiol Endod. 2006; 101 (3): e45-50.

46. Van Hinsbergh VW, Collen A, Koolwijk P. Role of fibrin matrix in angiogenesis. Ann NY Acad Sci. 2001; 936: 426-37.

47. Choukroun J, Diss A, Simonpieri A, Girard MO, Schoeffler C, Dohan SL, Dohan AJ, Mouhyi J, Dohan DM. Platelet-rich fibrin (PRF): a second generation platelet concentrate. Part IV: clinical effects on tissue healing. Oral Surg Oral Med Oral Pathol Oral Radiol Endod. 2006; 101(3): e56-60.

48. Dohan DM, Diss A, Odin G, Doglioli P, Hippolyte MP, Charrier JB. In vitro effects of Choukroun's PRF (platelet-rich fibrin) on human gingival fibroblasts, dermal prekeratinocytes, preadipocytes, and maxillofacial osteoblasts in primary cultures.
Oral Surg Oral Med Oral Pathol Oral Radiol Endod. 2009; 108: 341-52.

49. Wirthlin MR. The current status of new attachment therapy. J Periodontol. 1981; 52: 529-44.

50. Dohan DM, Rasmusson L, Albrektsson T. Classification of platelet concentrates: from pure platelet-rich plasma (P-PRP) to leucocyte-and platelet-rich fibrin (L-PRF). Trends Biotechnol. 2009; 27(3): 158-67.

51. Diss A, Dohan DM, Mouhyi J, Mahler P. Osteotome sinus flor elevation using Choukroun's platelet-rich fibrin as grafting material: a 1-year prospective pilot study with microthreaded implants. Oral Surg Oral Med Oral Pathol Oral Radiol Endod. 2008; 105(5): 572-9.

52. Simonpieri A, Del Corso M, Sammartino G, Dohan Ehrenfest DM. The relevance of Choukroun's Platelet-Rich Fibrin (PRF) and metronidazole during complex maxillary rehabilitations using bone allograft. Part II: implant surgery, prosthodontics and survival. Implant Dent. 2009; 18(3): 220-9.

53. M. Toffler, N. Toscano, D. Holtzclaw, M. Del Corso, and D. D. Ehrenfest, "Introducing Choukroun's platelet rich fibrin (PRF) to the reconstructive surgery milieu." The Journal of Implant and Advanced Clinical Dentistry. 2009; 1(6): 21-32.

54. Raja S, Munirathnam E. Platelet rich fibrin: Evolution of a second generation platelet concentrate. Indian J Dent Res. 2008; 19: 42-6.

55. Bajaj P, Nishanth S Rao, Agarwal E, Pradeep AR. Treatment of intrabony defect with platelet rich fibrin: Archives of Oral Sciences \& Research, AOSR. 2011; 1(2): 90-4. 